\title{
Fast fabrication of self-ordered anodic porous alumina on oriented aluminum grains by high acid concentration and high temperature anodization
}

\author{
Chuan Cheng ${ }^{1}$ and Alfonso H W Ngan \\ Department of Mechanical Engineering, The University of Hong Kong, Pokfulam Road, Hong \\ Kong, P. R. China \\ ${ }^{1}$ Author to whom any correspondence should be addressed chuan@hku.hk.
}

\begin{abstract}
Anodic porous alumina which exhibits a characteristic nanohoneycomb structure has been used in a wide range of nanotechnology applications. The conventional fabrication method of mild anodization (MA) requires prolonged anodization time which is impractical for batch processing, and self-ordered porous structures could only be formed within narrow processing windows so that the dimensions of the resultant structures are extremely limited. The alternative hard anodization (HA) may easily result in macroscopic defects on the alumina surface. In this work, by systematically varying the anodization conditions including the substrate grain orientation, electrolyte concentration, temperature, voltage, and time, a new oxalic-acid based anodization condition, called high acid concentration and high temperature anodization (HHA), is found, which can result in far better self-ordering of the porous structures at rates 7 to 26 times faster than the MA, under a continuous voltage range of $30-60 \mathrm{~V}$ on (001) oriented $\mathrm{Al}$ grains. Unlike $\mathrm{HA}$, no macroscopic defects appear under the optimum self-ordered condition of HHA at $40 \mathrm{~V}$, even for pore channels grown up to high aspect ratios $>3000$. Compared to MA and HA, the HHA provides more choices of self-ordered nano-porous structures with fast and mechanically stable formation features for practical applications.
\end{abstract}

PACS codes: 81.16.Dn, 81.16.Rf, 82.45.Yz, 81.07.-b

\section{Introduction}

Self-ordered anodic porous alumina, which is fabricated by anodization of aluminum with nanopores arranged in a quasi-periodic hexagonal pattern [1-5], has been widely used as templates for the synthesis of various nano-structured materials, such as nano-dots [6], nanowires [7, 8], nano-tubes [9, 10], especially for arrays of nano-elements whose collective behavior may not be realized by individual nano-elements [11, 12], such as phonic band gap crystals [13], nano-magnetic arrays [14, 15], nano-electronics [16], and so on.

Under the conventional mild anodization (MA), self-ordered anodic porous alumina can only be formed under certain narrow processing windows with specific values of the interpore distance $\left(D_{\text {int }}\right)$, such as $25 \mathrm{~V}$ in $0.3 \mathrm{M} \mathrm{H}_{2} \mathrm{SO}_{4}$ at $\sim 0{ }^{\circ} \mathrm{C}$ with $D_{\text {int }}=63 \mathrm{~nm} \mathrm{[17],} 40 \mathrm{~V}$ in $0.3 \mathrm{M} \mathrm{H}_{2} \mathrm{C}_{2} \mathrm{O}_{4}$ at $\sim 0$ ${ }^{\circ} \mathrm{C}$ with $D_{\text {int }}=100 \mathrm{~nm}$ [1], and $195 \mathrm{~V}$ in $0.3 \mathrm{M} \mathrm{H}_{3} \mathrm{PO}_{4}$ at $\sim 0{ }^{\circ} \mathrm{C}$ with $D_{\text {int }}=500 \mathrm{~nm}$ [18]. Selfordered anodic porous alumina with $<15 \mathrm{~nm}$ diameter and large aspect ratio has recently been 
fabricated by anodization in an ethylene-glycol-containing sulfuric acid electrolyte [19]. Due to the slow oxide growth rate (e.g. 2-6 $\mu \mathrm{m} \mathrm{h}^{-1}$ ) [2], prolonged anodization time of typically more than two days (e.g. $160 \mathrm{~h}$ ) was repaired under MA [1, 20]. Recently, hard anodization (HA) was regarded as a promising approach to replace the MA for fast (e.g. 50-100 $\mu \mathrm{m} \mathrm{h}^{-1}$ ) and self-ordered porous alumina fabrication [2, 20-24]. However, because of the high anodization voltages of HA (generally 2 to 3 times higher than that of $\mathrm{MA}$, e.g. $40-80 \mathrm{~V}$ for $\mathrm{H}_{2} \mathrm{SO}_{4}$ electrolyte at $0 \pm 1{ }^{\circ} \mathrm{C}$ [20, 21], $100-160 \mathrm{~V}$ for $\mathrm{H}_{2} \mathrm{C}_{2} \mathrm{O}_{4}$ electrolyte at $1{ }^{\circ} \mathrm{C}[2,22]$ ), the very rapid heat generation caused by the high electric field across the oxide barrier layer was difficult to be dissipated quickly [25, 26], and as a result, many macroscopic burns or cracks, observable even by the naked eye, may form on the alumina surface [20,21]. Furthermore, direct anodization under HA may result in disordering pore arrangements [2]. To solve these problems, Lee et al. [2] and Schwirn et al. [20] first conducted anodization under MA for several minutes to generate a protective oxide layer and then gradually increase the voltage to the target high voltage of $\mathrm{HA}$, and as a result macroscopic burns or cracks were eliminated. However, under $\mathrm{HA}$ with $\mathrm{H}_{2} \mathrm{SO}_{4}$ electrolyte, macroscopic corrugations were found to extend across the entire surface of the alumina sample, indicating the possibility of plastic deformations in the porous alumina or Al substrate [20]. Thus, fast and mechanically stable fabrication of anodic porous alumina with self-ordered pore arrangement is still a challenge.

In this paper, we systematically investigated the key influencing factors of self-ordered anodic porous alumina formation, in order to find alternative processing windows for selfordering with fast and mechanically stable alumina growth features. These factors are electrolyte $\left(\mathrm{H}_{2} \mathrm{C}_{2} \mathrm{O}_{4}\right)$ concentration, temperature, voltage, time, and substrate grain orientation, especially the last factor was recently found by $\mathrm{Ng}$ and $\mathrm{Ngan}$ [5, 27, 28] and Beck et al. [29, 30] independently, and further confirmed by Napolskii et al. [31]. Specifically, the best self-ordered anodic porous alumina can be formed on the (001) oriented Al grains. However, systematic investigation of the combined effects of above factors on the self-ordered anodic porous alumina formation has not been reported. We will show that beside the MA and HA conditions, an alternative condition, referred to as "high acid concentration and high temperature anodization (HHA)" condition, can result in far better self-ordered porous patterns on (001) oriented $\mathrm{Al}$ grains under the continuous anodization voltage range of 30-60 V in $\mathrm{H}_{2} \mathrm{C}_{2} \mathrm{O}_{4}$ electrolyte, with an oxide growth rate 7-26 times faster than that in MA. Moreover, macroscopic burns, cracks, or corrugations that may appear under the HA condition [20, 21] are not observed in the porous alumina formed under HHA condition at the optimum self-ordered voltage $(40 \mathrm{~V})$, even though the aspect ratio of the pore channels is larger than 3000. Furthermore, the relationship between $D_{\text {int }}$ and the anodization voltage is nonlinear under HHA condition, which is much different from the well-known linear relationship under MA or HA condition [2, 32]. The HHA condition provides more choices of self-ordered anodic porous alumina with $D_{\text {int }}$ from 74.5 to $112.0 \mathrm{~nm}$ with fast and mechanically stable formation features for practical applications [33-36].

\section{Methods section}

\subsection{Anodization of aluminum}

Pure polycrystalline aluminum foils (99.99\%, $1 \mathrm{~mm}$ in thickness and 1 inch in diameter) were annealed under vacuum ( $\sim 10^{-5}$ torr) at $500{ }^{\circ} \mathrm{C}$ for $48 \mathrm{~h}$, then mechanically polished with 1200 , 2400, 4000 grit $\mathrm{SiC}$ sandpapers and $6 \mu \mathrm{m}, 1 \mu \mathrm{m}$ diamond pastes in succession, and finally electropolished in a mixture solution of $\mathrm{HClO}_{4}\left(60 \%\right.$ wt) and $\mathrm{C}_{2} \mathrm{H}_{5} \mathrm{OH}$ with in $1: 4$ ratio by volume under $20 \mathrm{~V}$ at about $-10{ }^{\circ} \mathrm{C}$ for $2 \mathrm{~min}$. Anodization experiments were conducted within oxalic acid $\left(\mathrm{H}_{2} \mathrm{C}_{2} \mathrm{O}_{4}\right)$ under potentiostatic conditions (constant anodization voltage) in a large electrochemical cell (2 L) in a constant temperature environment achieved by an electronic feedback controlled water bath. The $\mathrm{Al}$ foils were mounted on a copper plate serving as the anode, while the cathode is an array of carbon rods placed $\sim 10 \mathrm{~cm}$ from the anode. In order to 
systematically investigate the dependence of self-ordering on different anodization conditions, we used anodization voltage from 10 to $60 \mathrm{~V}$, oxalic acid $\left(\mathrm{H}_{2} \mathrm{C}_{2} \mathrm{O}_{4}\right)$ concentration from 0.05 to $1 \mathrm{M}$, temperature from 2 to $20{ }^{\circ} \mathrm{C}$, and anodization time from a few minutes to $23 \mathrm{~h}$ for one step anodization. The conditions for a particular AAO sample will be specified when it is first mentioned below. For two-step anodization, in order to selectively dissolve anodic porous alumina formed in the $1^{\text {st }}$ step, the samples were put into a mixed solution of $\mathrm{H}_{2} \mathrm{CrO}_{4}, \mathrm{H}_{3} \mathrm{PO}_{4}$ and $\mathrm{H}_{2} \mathrm{O}$ with composition $1.8: 6: 92.2$ by weight at $60{ }^{\circ} \mathrm{C}$. After that, the $2^{\text {nd }}$ step anodization was conducted under the same conditions as in the $1^{\text {st }}$ step.

\subsection{Microscopic characterization}

After anodization the formed anodic porous alumina was first selectively dissolved as stated above. Then, macroscopic and distinguishable markers were made by pen on the Al substrates to ease the identification of the grains of interest (e.g. figures S1 (a)-(c)). After that, electron backscattered diffraction (EBSD) maps of the Al substrate were obtained in a LEO 1530 fieldemission scanning electron microscope (FE-SEM). Then, targeted Al grains, such as (001), (101), and (111) orientated grains, were identified in the EBSD (e.g. figures 1(a)-(c)). If the targeted grain did not fall close to or in contact with some distinguishable markers (e.g. figure 1(c)), more additional markers were added around that grain, and then EBSD will be performed again. In this way, the targeted grain can be easily located according to its relative location with respect to its neighboring macroscopic markers. Next, SEM examination was carried out in a Hitachi S-4800 field-emission microscope in order to obtain the bottom patterns formed on the selected Al grains (e.g. figures 1(d)-(f)) The above procedure provides a convenient and low cost method (e.g. compared with focused ion beam marking of metal grains [37]) for capturing patterns formed on different oriented grains, so that many series of anodization experiments can be conducted to systematically investigate the key influencing factors on the formation of self-ordered anodic porous alumina.

\subsection{Quantitative evaluation of porous patterns'ordering}

The porous pattern was quantitatively characterized by a method based on the orientations of triangles connecting three neighboring pore centers of the pattern [38], which was further developed from Hillebrand et al. [39] and Mátéfi-Tempfli et al. [40]. Firstly, the coordinates of the pore centers in the porous pattern were captured by the ImagJ software [41]. Secondly, three neighboring pore centers were connected to form a triangle, and the whole pattern becomes a triangular mesh. Thirdly, each triangle's orientation factor $\theta$ (with the horizontal boarder of the SEM image as the reference direction) is calculated as

$$
\theta=\frac{1}{3}\left[\operatorname{atan}\left(\frac{y_{1}-y_{2}}{x_{1}-x_{2}}\right)+\operatorname{atan}\left(\frac{y_{2}-y_{3}}{x_{2}-x_{3}}\right)+\operatorname{atan}\left(\frac{y_{3}-y_{1}}{x_{3}-x_{1}}\right)\right] \frac{180^{\circ}}{\pi},
$$

where $\left(x_{i}, y_{i}\right), i=1,2,3$, are the coordinates of three vertices of the triangle. Most of the triangles in a mildly disordered pattern usually have $\theta$ falling in the range $\left[-30^{\circ}, 30^{\circ}\right]$, but if $\theta$ exceeds this range, it is reduced to within $\left[-30^{\circ}, 30^{\circ}\right]$ by adding or subtracting $60^{\circ}$, because the mesh structure is a hexagonal arrangement of the triangles. The triangles are then colored according to their $\theta$ values with the wrapping scale shown at the bottom of figure 1(i), in which $-30^{\circ}$ and $30^{\circ}$ correspond to the same (red) color. For triangles locating at point defects, or ordered zone boundaries, or with shapes much deformed from an equilateral triangle, they were eliminated from the ordered zone size calculation. To realize the elimination, for a triangle, the standard deviation of its three edges and three angles are calculated as

$$
\text { Dev_d }=\frac{1}{\bar{d}} \sqrt{\frac{1}{3} \sum_{i=1}^{3}\left(d_{i}-\bar{d}\right)^{2}},
$$




$$
D e v_{-} \phi=\frac{1}{\bar{\phi}} \sqrt{\frac{1}{3} \sum_{i=1}^{3}\left(\phi_{i}-\bar{\phi}\right)^{2}},
$$

where $d_{i}$ and $\phi_{i}(i=1,2,3)$ are the edge lengths and angle sizes of that triangle, and $\bar{d}$ is the mean of $d_{i}$, and $\bar{\phi}$ is the mean of $\phi_{i}$. A triangle will be considered as falling within an ordered zone of the pattern and be colored only if $D e v \_d>T o l \_d$ and $D e v \_\phi>T o l \_\phi$, where Tol_d and Tol_$\phi$ are tolerance factors; otherwise it will be filled with white color. According to our previous experience [38] and Refs. 39 and 40, in this paper, we used the same value Tol_d $=0.1$ and Tol_ $\phi$ $=0.1$ to evaluate the ordered zone sizes of all patterns. Note that this is a rather strict criterion; however, it is only under the same criterion for all patterns that the ordering qualities can be reliably compared. Examples of colored patterns with Tol_ $d=0.2$ and Tol_ $\phi=0.2$ are shown in figures S6 and S7, and such relatively higher tolerance factors were used only for clear illustration of colored patterns but not for ordered zone size calculation. In addition, because in real porous patterns, neighboring triangles within the same ordered zone may not have exactly the same orientation $\theta$, and in order to distinguish different ordered zones in a pattern, we employed another tolerance parameter Tol_ $\theta$, which means that two neighboring triangles are regarded as within the same ordered zone if their orientation difference $\Delta \theta<T o l \_\theta$. In this paper, the same criterion Tol $\theta=3^{\circ}$ was used for all patterns evaluation.
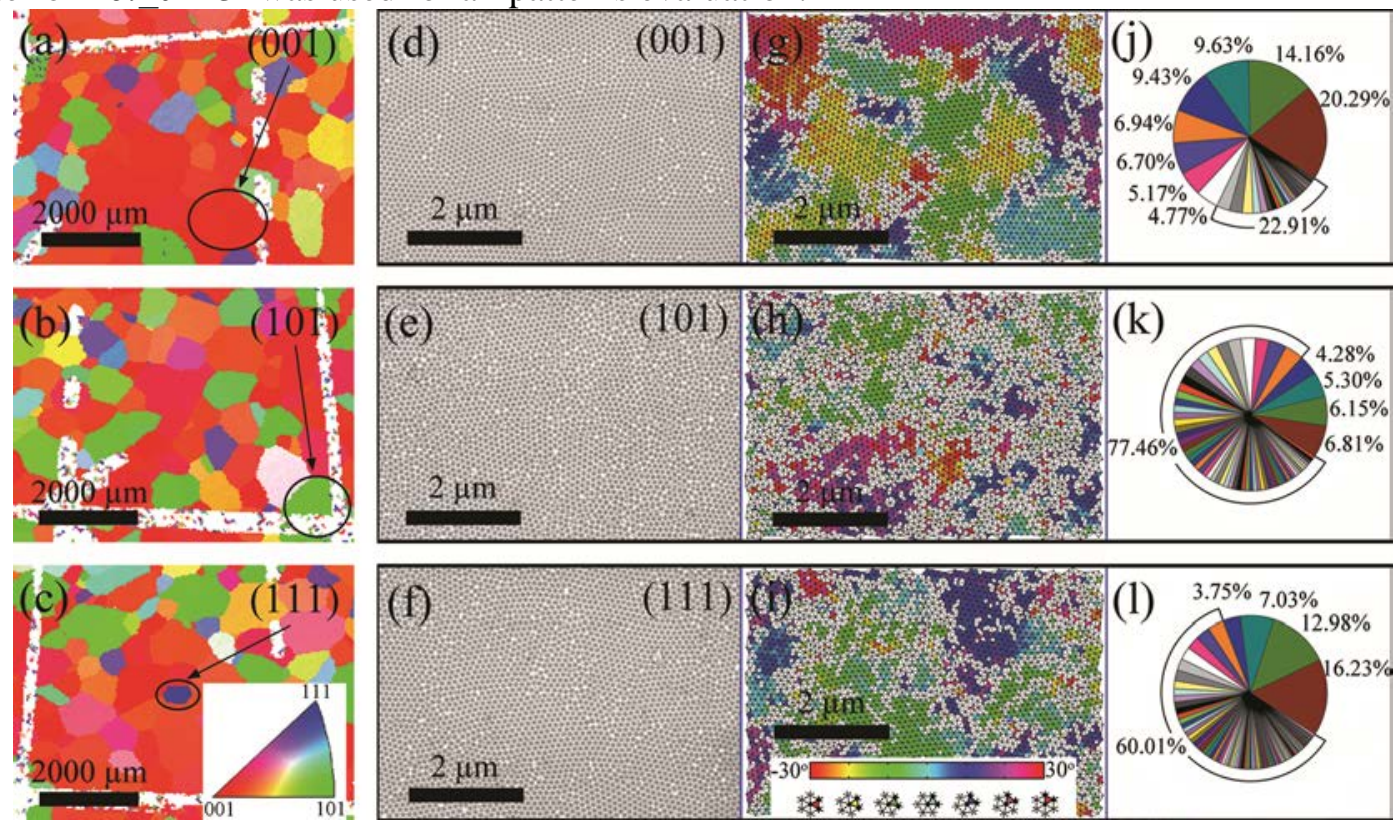

Figure 1. (a)-(c) EBSD maps of $\mathrm{Al}$ substrate showing crystallographic orientations of grains. After anodization $\left(40 \mathrm{~V}, 0.5 \mathrm{M} \mathrm{H}_{2} \mathrm{C}_{2} \mathrm{O}_{4}, 5{ }^{\circ} \mathrm{C}, 1^{\text {st }}\right.$ step $3 \mathrm{~h}, 2^{\text {nd }}$ step $\left.16 \mathrm{~h}\right)$ the anodic porous alumina on $\mathrm{Al}$ substrate has been selectively dissolved. White lines are distinguishable markers helping to target $\mathrm{Al}$ grains. (d)-(f) SEM of bottom porous patterns formed on the corresponding $\mathrm{Al}$ grains as labeled in (a)-(c). (g)-(i) Coloring of the corresponding patterns in (d)-(f). (j)-(l) Pie charts representing the relative sizes of 43,64 and 80 ordered zones in patterns of (g)-(i), respectively.

\section{Results and discussion}

\subsection{Substrate grain orientation dependent self-ordering of porous patterns}

Figure 1 illustrates a typical procedure for quantitative evaluation of pore arrangements in anodic porous alumina formed on (001), (101), and (111) oriented Al grains. After anodization (40 V, 0.5 
$\mathrm{M} \mathrm{H}_{2} \mathrm{C}_{2} \mathrm{O}_{4}, 5^{\circ} \mathrm{C}, 1^{\text {st }}$ step $3 \mathrm{~h}, 2^{\text {nd }}$ step $16 \mathrm{~h}$ ), the anodic porous alumina on top was selectively dissolved. Because of the scalloped shape of the oxide barrier layer at the pores' bottom ${ }^{1-5}$, each pore will leave behind a small dimple on the Al substrate. Thus, the "bottom porous pattern" left on the substrate, as shown in figures 1(d)-(f), should directly reflect the arrangement of the pores at the end of the anodization. After ordering characterization, a porous pattern can be divided into tens of ordered zones each filled with similar colors (figures 1(g)-(i)) according to the orientation factor $\theta$ of the composing triangles (see section 2), while deformed triangles compared with equilateral triangles are filled with white color. The relative sizes of the ordered zones in each pattern of figures $1(\mathrm{~g})$-(i) are illustrated in the pie charts of figures 1(j)-(l), respectively. From figures 1(g)-(l), the porous pattern formed on (001) oriented Al grain has obviously better ordering quality than those formed on (101) and (111) oriented grains, not only because more areas of the pattern are colored (ordered), but also the relative sizes of the largest ordered zones (e.g. $20.92 \%, 14.16 \%, 9.63 \%$ for the $1^{\text {st }}, 2^{\text {nd }}, 3^{\text {rd }}$ largest zones in figure $1(j)$ ) are much larger than those on (101) and (111) oriented grains (figures 1(k) and (l)). Under the present anodization condition, the ordering rank is $(001)>(111)>(101)$. Ng and Ngan reported that the ordering quality of patterns formed on other oriented grains was between those on (001) and (101) grains which represent the best and the worst extremes, respectively [5]. Thus, in the present work, we mainly focus on the two ends, namely, patterns formed on (001) and (101) oriented grains, and investigate the combined effects of anodization conditions on the ordering qualities of the porous patterns.

\subsection{Acid concentration dependent self-ordering of porous patterns}

For groups of porous patterns formed under various anodization conditions (different patterns may have different interpore distance $D_{\text {int }}$ ), the average ordered zone size of a pattern in calculated, and then normalized by dividing by $\left(D_{\text {int }} \times D_{\text {int }}\right)$ of that pattern. $D_{\text {int }}$ is obtained from the first peak position of the radial distribution function (RDF) curve, which is plotted based on the pore center coordinates of the pattern (details see figure S1 (d)-(f)). Then, we have a quantitative ordering factor called "normalized average ordered zone size (NAOZS)", which can be interpreted as the average number of $\left(D_{\text {int }} \times D_{\text {int }}\right)$ squares in the ordered zones of that pattern. In order to improve the reliability of the results, three to ten SEM images with the same magnification $(20 \mathrm{~K})$, comprising $\sim 1 \times 10^{4}$ to $3 \times 10^{4}$ pores in total, were captured at different locations on the same oriented Al grain, and from each image a NAOZS value was obtained. The "Error bars" are used to represent the spread of NAOZS for patterns captured on the same oriented $\mathrm{Al}$ grain.
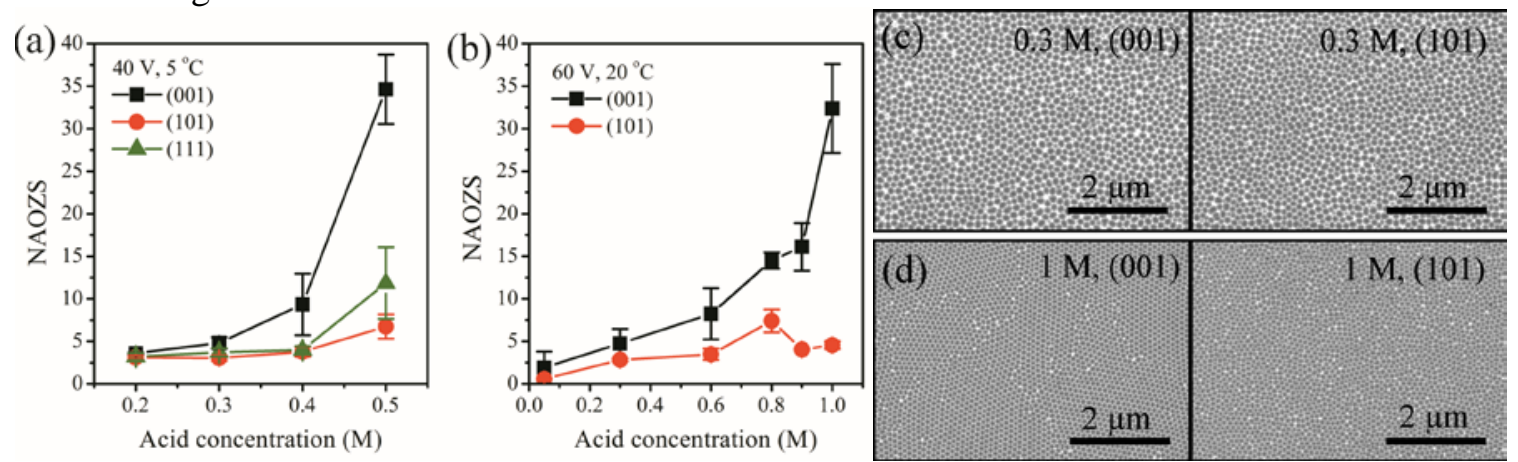

Figure 2. Normalized average ordered zone size (NAOZS) of bottom porous patterns formed on (a) (001), (101), and (111) oriented Al grains, (b) (001) and (101) oriented Al grains, against acid $\left(\mathrm{H}_{2} \mathrm{C}_{2} \mathrm{O}_{4}\right)$ concentration. Anodization conditions are (a) the same as figure 1 ; (b) $60 \mathrm{~V}$ at $20{ }^{\circ} \mathrm{C}$. SEM of bottom porous patterns formed under $60 \mathrm{~V}, 20^{\circ} \mathrm{C}$, (c) $0.3 \mathrm{M}$, (d) $1 \mathrm{M}$, on (001) and (101) orientated $\mathrm{Al}$ grains. Additional SEM images are shown in figures S2 and S3. 
Figure 2(a) shows that with acid concentration increasing, while all other anodization conditions are kept the same $\left(40 \mathrm{~V}, 5{ }^{\circ} \mathrm{C}, 3 \mathrm{~h}\right.$ for $1^{\text {st }}$ step, $16 \mathrm{~h}$ for $2^{\text {nd }}$ step), the NAOZS monotonically increases, with the increasing extent highly dependent on Al grain orientation. Specifically, the NAOZS on (001) oriented grain is more sensitive to acid concentration, as this increases by about ten times (from 3.6 to 34.6) when the acid concentration increases from $0.2 \mathrm{M}$ to $0.5 \mathrm{M} \mathrm{H}_{2} \mathrm{C}_{2} \mathrm{O}_{4}$; while this value only increases by about two times and four times for (101) and (111) oriented grains, respectively. Similarly, in another group of anodization conducted under 60 $\mathrm{V}, 20{ }^{\circ} \mathrm{C}$, with acid concentration increasing from $0.05 \mathrm{M}$ to $1 \mathrm{M} \mathrm{H}_{2} \mathrm{C}_{2} \mathrm{O}_{4}$ (figure 2(b)), the NAOZS of patterns formed on (001) grains increases quickly and monotonically by about 17 times (from 1.9 to 32.4), while that on (101) oriented grains only changes slightly. Under lower acid concentrations (e.g. $\leq 0.3 \mathrm{M})$ in figure 2, the ordering between patterns formed on different oriented grains is quite similar (with low NAOZS $<5$ ), which corresponds to very disordered patterns (figures 2(c), S2, and S3). If experiments are only conducted within such a low acid concentration range, then an apparent conclusion of the pattern ordering being independent of $\mathrm{Al}$ grain orientation would be made [42]. However, due to the acid concentration sensitivity, the advantage of (001) substrate orientation for better self-ordering pattern formation becomes much obvious under higher acid concentrations of each anodization group (e.g. figure 2(d)). Previously, the windows for self-ordered porous pattern formation were regarded to be very narrow (e.g. 40 $\mathrm{V}, 0.3 \mathrm{M} \mathrm{H}_{2} \mathrm{C}_{2} \mathrm{O}_{4}$ under MA [1], or $140 \mathrm{~V}, 0.3 \mathrm{M} \mathrm{H}_{2} \mathrm{C}_{2} \mathrm{O}_{4}$ under HA [2]). However, $60 \mathrm{~V}$, which has never been regarded as a self-ordered voltage in $\mathrm{H}_{2} \mathrm{C}_{2} \mathrm{O}_{4}$ based anodization, can result in wellordered patterns on (001) oriented $\mathrm{Al}$ grains if the acid concentration is high enough to be $1 \mathrm{M}$ (figure 2(d)).
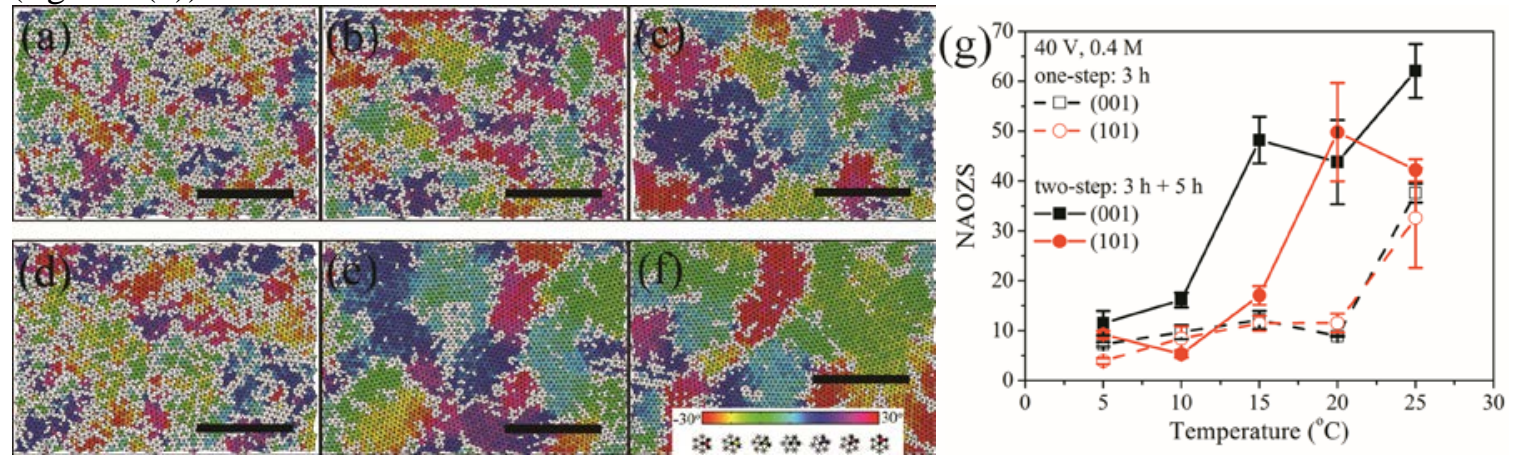

Figure 3. (a)-(f) Colored bottom porous patterns formed on (001) oriented Al grains after selectively dissolving anodic porous alumina on top (scale bar $=2 \mu \mathrm{m}$ ). The corresponding SEM patterns are shown in figure S4. Anodizations are conducted under $40 \mathrm{~V}, 0.4 \mathrm{M} \mathrm{H}_{2} \mathrm{C}_{2} \mathrm{O}_{4}$, for (a)(c) one-step ( $3 \mathrm{~h})$, and (d)-(f) two-step $\left(1^{\text {st }}\right.$ step $3 \mathrm{~h}$ and $2^{\text {nd }}$ step $\left.5 \mathrm{~h}\right)$, at the temperature of (a, d) 5 ${ }^{\circ} \mathrm{C}$, (b, e) $15{ }^{\circ} \mathrm{C}$, and (c, f) $25{ }^{\circ} \mathrm{C}$. (g) Normalized average ordered zone size (NAOZS) of the bottom patterns formed on (001) and (101) oriented Al grains against temperature.

\subsection{Temperature dependent self-ordering of porous patterns}

Figures 3(a)-(f) illustrate colored bottom porous patterns formed on (001) oriented Al grains with temperature increasing from $5{ }^{\circ} \mathrm{C}$ to $25{ }^{\circ} \mathrm{C}$, while all other anodization conditions were the same, i.e. $40 \mathrm{~V}, 0.4 \mathrm{M} \mathrm{H}_{2} \mathrm{C}_{2} \mathrm{O}_{4}, 3 \mathrm{~h}$ for one-step case, and $3 \mathrm{~h}+5 \mathrm{~h}$ for two-step case. From the quantitative data in figure 3(g), under one-step anodization, the NAOZS increases from 7.3 at 5 ${ }^{\circ} \mathrm{C}$ to 37.7 at $25{ }^{\circ} \mathrm{C}$, corresponding to about 5 times of ordering improvement; similarly, for the two-step anodization, NAOZS increases from 11.6 at $5{ }^{\circ} \mathrm{C}$ to 62.1 at $25{ }^{\circ} \mathrm{C}$, also about 5 times of ordering improvement. However, if we compare figures 3(a)-(c) with figures 3(d)-(f) under the same temperature, the ordered zone size in the latter is obviously larger than the former, and this is only due to the additional anodization step for $5 \mathrm{~h}$. This seems to indicate that more anodization time (or steps) can improve a pattern's ordering, but does not necessarily mean that the 
improvement can be monotonously on going, as otherwise the whole porous pattern will develop into a single well-ordered hexagonal zone if the time is long enough (for details see figure 8). For patterns formed on (101) Al grains, figure 3(g) shows that the NAOZS also increases with temperature for both one-step and two-step cases but have smaller NAOZS than those formed on (001) grains. Furthermore, the difference of NAOZS between patterns on (001) and (101) grains are very small for one-step anodization, in contrast with the obvious difference for two-step anodization. This means the advantage of (001) substrate orientation for better ordered pattern formation exists only when the anodization time is long enough. In addition, another group of anodzation under higher acid concentrations $\left(0.8 \mathrm{M} \mathrm{H}_{2} \mathrm{C}_{2} \mathrm{O}_{4}\right)$ was also conducted (not shown here), and the same increasing tendency of NAOZS with temperature was also observed for patterns formed on both (001) and (101) oriented $\mathrm{Al}$ grains.
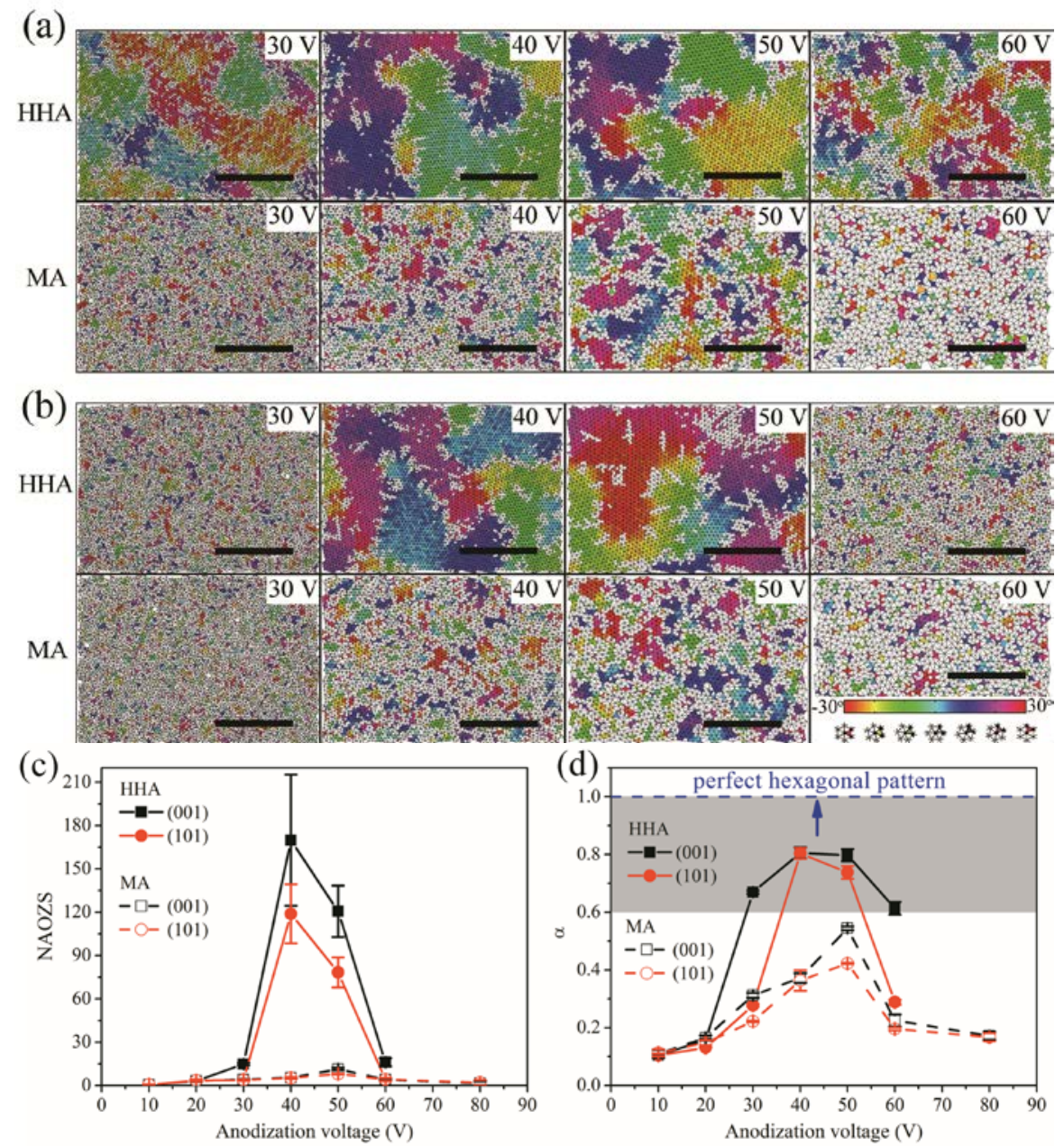

Figure 4. Colored bottom porous patterns formed on (a) (001) and (b) (101) oriented Al grains under $\mathrm{HHA}\left(0.9 \mathrm{M} \mathrm{H}_{2} \mathrm{C}_{2} \mathrm{O}_{4}, 20{ }^{\circ} \mathrm{C}\right.$ ) and $\mathrm{MA}\left(0.3 \mathrm{M} \mathrm{H}_{2} \mathrm{C}_{2} \mathrm{O}_{4}, 2^{\circ} \mathrm{C}\right.$ ) conditions (scale bar $=2 \mu \mathrm{m}$ ). The corresponding SEM patterns are shown in figure S5. Two-step anodizations are conducted under HHA at $30 \mathrm{~V}(8 \mathrm{~h}+4 \mathrm{~h}), 40 \mathrm{~V}(3.5 \mathrm{~h}+1.75 \mathrm{~h}), 50 \mathrm{~V}(45 \mathrm{~min}+23 \mathrm{~min}), 60 \mathrm{~V}(10 \mathrm{~min}+5$ $\mathrm{min})$; and under MA at $30 \mathrm{~V}, 40 \mathrm{~V}, 50 \mathrm{~V}, 60 \mathrm{~V}$ (2 h + 1h for each voltage). (c) Normalized average ordered zone size (NAOZS) against anodization voltage. (d) $\alpha$ (= sum of ordered zone areas of the pattern/total area of the pattern) against anodization voltage.

\subsection{Voltage dependent self-ordering of porous patterns under HHA and MA conditions}

According to sections 3.1 to 3.3, a relatively high acid concentration or high temperature alone, compared to the $\sim 0.3 \mathrm{M} \mathrm{H}_{2} \mathrm{C}_{2} \mathrm{O}_{4}$ and $\sim 0{ }^{\circ} \mathrm{C}$ for MA or HA [1, 2, 22], can obviously improve the 
porous patterns' ordering, especially for those formed on (001) oriented Al grains. In the following, the above two factors are combined to form a so-called "high acid concentration and high temperature anodization (HHA)" condition, with $0.9 \mathrm{M} \mathrm{H}_{2} \mathrm{C}_{2} \mathrm{O}_{4}$ at $20{ }^{\circ} \mathrm{C}$. Under this condition, as shown in figure 4, the selected anodization time decreases with anodization voltage in order to similar anodic oxide thickness for each porous structure. For comparison, anodizations experiments under a conventional MA condition with $0.3 \mathrm{M} \mathrm{H}_{2} \mathrm{C}_{2} \mathrm{O}_{4}$ at $2{ }^{\circ} \mathrm{C}$ were also conducted. Figure 4(a) shows the bottom porous patterns formed on (001) oriented Al grains under HHA and MA, respectively, with voltage ranging from 30 to $60 \mathrm{~V}$. We can see that the ordered zones formed under HHA are always larger than those formed under MA at the same voltage. This situation is also observed for patterns formed on (101) oriented Al grains (figure 4(b)). The difference between (001) and (101) oriented grains is that the former can lead to better ordered patterns than the later under the same HHA or MA condition. In addition, for the same $\mathrm{Al}$ orientation and the same HHA condition, the size of the ordered zones first increases from $30 \mathrm{~V}$ to $40 \mathrm{~V}$ and then decreases from $40 \mathrm{~V}$ to $60 \mathrm{~V}$, as quantitatively shown in figure 4(c). The optimum condition for best ordering in these HHA and MA groups is HHA $40 \mathrm{~V}$ on (001) substrate orientation, with NAOZS (= 169.8) about 32 times larger than that of MA $40 \mathrm{~V}$ on (001) substrate orientation. In figure 4(d), $\alpha$ represents the sum of the ordered zones' areas in a pattern to the total area of that pattern, which serves as another ordering qualification parameter besides the NAOZS. Under HHA, within the continuous voltage range of 30-60 V, the corresponding $\alpha$ values are all larger than 0.6 (covered by the gray region in figure $4(\mathrm{~d})$ ), which means that more that $60 \%$ of the area of a pattern is hexagonally ordered, under a rather strict criterion for ordering (see section 2). Especially, for patterns formed under HHA $40 \mathrm{~V}$ on both (001) and (101) Al grains, $\alpha$ is about 0.8 which is quite close to the ideal case of 1 . Note that patterns formed on (101) oriented $\mathrm{Al}$ grains generally have the worst ordering among all possible substrate orientations in a polycrystalline $\mathrm{Al}$ foil [5], thus HHA $40 \mathrm{~V}$, which is the optimum self-ordered condition within the above HHA and MA groups, can significantly reduce the dependence of the ordering on substrate orientation and result in very homogenous self-ordered patterns on the whole polycrystalline Al foil (also see figures S6 and S7). This will definitely avoid the complexities involved in detecting $\mathrm{Al}$ grain orientations by EBSD for the fabrication of selfordered anodic porous alumina. 


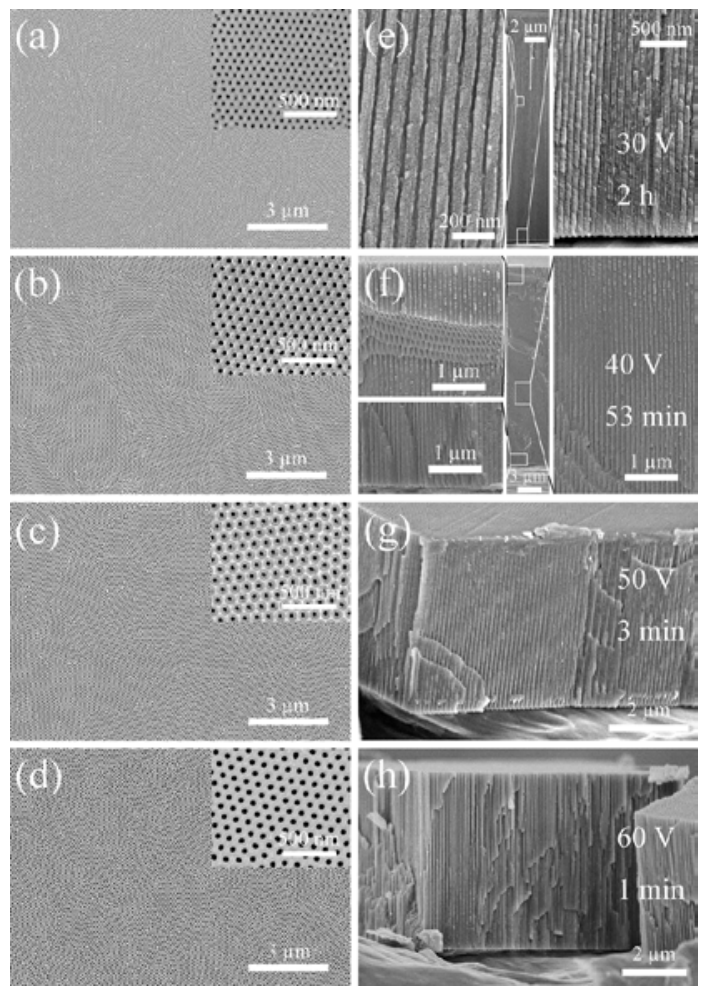

Figure 5. Self-ordered anodic porous alumina formed under continuous voltage range of 30-60 V under HHA (0.9 $\mathrm{M} \mathrm{H}_{2} \mathrm{C}_{2} \mathrm{O}_{4}, 20{ }^{\circ} \mathrm{C}$ ). (a)-(d) Top view of anodic porous alumina formed on (001) oriented $\mathrm{Al}$ grains after the $3^{\text {rd }}$ anodization step with $2 \mathrm{~h}(30 \mathrm{~V}), 53 \min (40 \mathrm{~V}), 3 \min (50 \mathrm{~V})$, and $1 \mathrm{~min}(60 \mathrm{~V})$, respectively. The previous two-step anodization has been shown in figure 4(a) HHA. Colored patterns corresponding to (a)-(d) are shown in figure S6. (e)-(h) Side views of anodic porous alumina under the same HHA conditions as (a)-(d), but the grain orientation of the $\mathrm{Al}$ substrate is not specified.

After obtaining the bottom porous patterns on the Al substrates (figures 4(a) and (b)), an additional $\left(3^{\text {rd }}\right)$ anodization step was conducted under the same conditions as the previous two steps. Anodic porous alumina which directly inherited the bottom porous patterns on the $\mathrm{Al}$ substrates was formed. figures 5(a)-(d) illustrate the top views of anodic porous alumina formed on (001) oriented $\mathrm{Al}$ grains under HHA condition, while the corresponding colored patterns are shown in figure S6. From these figures, self-ordered anodic porous alumina patterns are formed under the continuously voltage range of $30-60 \mathrm{~V}$. The anodic porous alumina samples were fractured (with the $\mathrm{Al}$ substrate grain orientation unspecified) to exam the cross-sectional views of the porous structures. As shown in figures 5(e)-(h), the pore channels are straight from pores' top to bottom, without termination or splitting which were frequently observed in disordered anodic porous alumina [5, 32, 43]. Furthermore, the $D_{\text {int }}$ changes nonlinearly with the anodization voltage under HHA (details in figure 6(b)), which is $74.5 \mathrm{~nm}$ at $30 \mathrm{~V}, 96.0 \mathrm{~nm}$ at $40 \mathrm{~V}, 111.6 \mathrm{~nm}$ at $50 \mathrm{~V}$, and $112.0 \mathrm{~nm}$ at $60 \mathrm{~V}$. Note that under the conventional MA condition with $\mathrm{H}_{2} \mathrm{C}_{2} \mathrm{O}_{4}$ as electrolyte, self-ordered porous alumina can only be formed under $40 \mathrm{~V}$ with a specific $D_{\text {int }}=100$ $\mathrm{nm}$, after typically more than two days of anodization time $[1,20]$. Instead, the HHA condition extends such a narrow self-ordering window to a much wider range (30-60 V and $D_{\text {int }}=74.5$ to $112.0 \mathrm{~nm}$ ), corresponding to much wider choices of self-ordered structures for various nanotechnology applications [33-36]. 

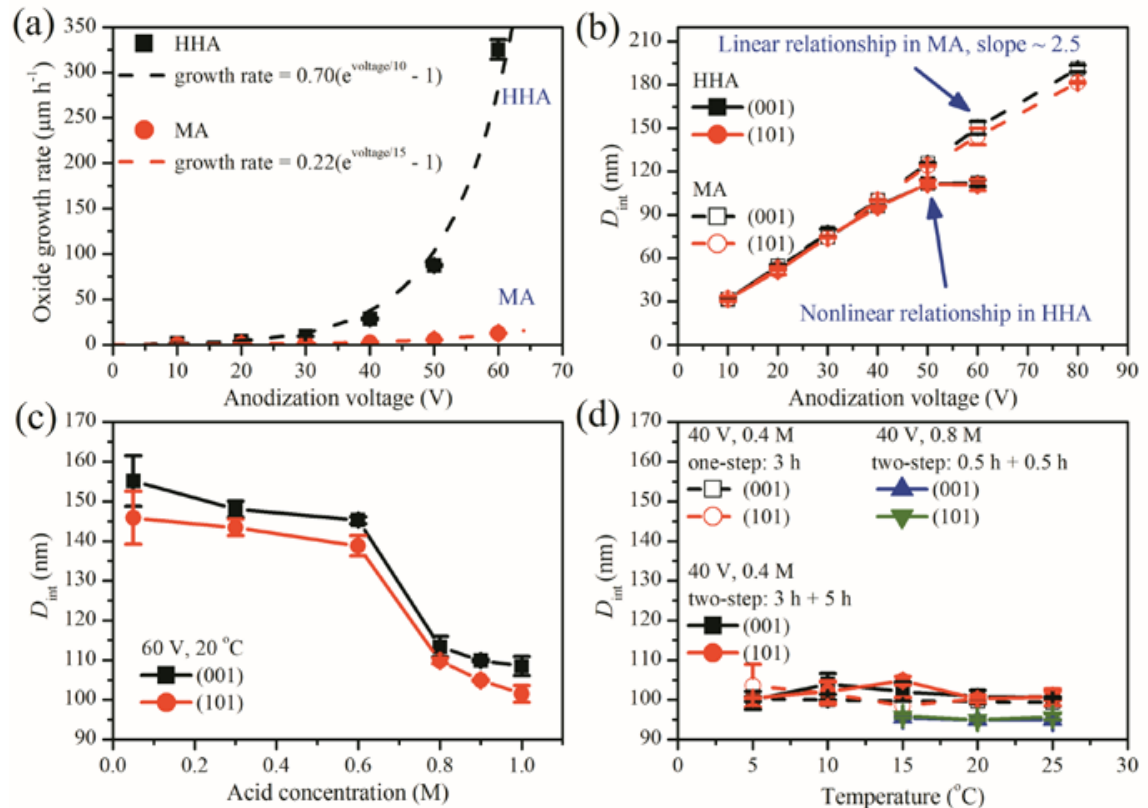

Figure 6. (a) Oxide growth rate, and (b) interpore distance $\left(D_{\text {int }}\right)$ against anodization voltage for anodic porous alumina formed under $\mathrm{HHA}\left(0.9 \mathrm{M} \mathrm{H}_{2} \mathrm{C}_{2} \mathrm{O}_{4}, 20{ }^{\circ} \mathrm{C}\right)$ and $\mathrm{MA}\left(0.3 \mathrm{M} \mathrm{H}_{2} \mathrm{C}_{2} \mathrm{O}_{4}, 2{ }^{\circ} \mathrm{C}\right)$ conditions. (c) and (d) $D_{\text {int }}$ against acid $\left(\mathrm{H}_{2} \mathrm{C}_{2} \mathrm{O}_{4}\right)$ concentration and temperature, respectively.

The HHA condition is not only beneficial for achieving highly self-ordered porous patterns under a wide range of voltages, but also for the much faster oxide growth rate compared with MA condition. For example, to obtain the self-ordered porous structure shown in figure 5(h) (HHA 60 V), the total anodization time was only $16 \mathrm{~min}$, including $1^{\text {st }}$ step $10 \mathrm{~min}, 2^{\text {nd }}$ step $5 \mathrm{~min}$, and $3^{\text {rd }}$ step $1 \mathrm{~min}$. For only $1 \mathrm{~min}$ (figure 5(h)), the porous alumina grew up to $\sim 5.2 \mu \mathrm{m}$ thickness with each pore developing straightly from top to bottom. This rate is about 26 times faster than the rate of MA under the same voltage $60 \mathrm{~V}$ (figure 6(a)); however, MA $60 \mathrm{~V}$ can only result in disordered patterns (figure 4(a) MA $60 \mathrm{~V}$ ). As shown in figure 6(a), under HHA the oxide growth rate is exponentially proportional to voltage according to $0.70 \mathrm{e}^{\text {voltage } / 10}$, which is about $3.18 \mathrm{e}^{\text {voltage/30 }}$ times faster than that under MA for which the oxide growth rate $\left(\propto 0.22 \mathrm{e}^{\text {voltage/15 }}\right)$. This also means the higher the voltage, the larger the rate difference between HHA and MA, and as a result, from 30 to $60 \mathrm{~V}$ the oxide growth rate of HHA is about 7 to 26 times faster than that of MA. Yet, HHA can continuously result in well-ordered patterns in this voltage range (figures 4, 5(a-d)), while MA can only result in well-ordered patterns under $40 \mathrm{~V}$ [1]. Figure 6(b) shows the $D_{\text {int }}$ of patterns formed on (001) and (101) Al grains against anodization voltage under HHA and MA conditions, respectively. In contrast to the well-known linear relationship between $D_{\text {int }}$ and voltage under MA (slope $~ 2.5 \mathrm{~nm} \mathrm{~V}^{-1}$, figure 6(b) MA) or HA (slope $\sim 2.0 \mathrm{~nm} \mathrm{~V} \mathrm{~V}^{-1}$ [2]), the relationship is nonlinear from 30 to $60 \mathrm{~V}$ under HHA (figure 6(b) HHA). The $D_{\text {int }}$ to voltage ratio decreases with voltage under HHA for patterns on both (001) and (101) oriented grains, which are $2.5 \mathrm{~nm} \mathrm{~V}^{-1}$ at $30 \mathrm{~V}, 2.4 \mathrm{~nm} \mathrm{~V}^{-1}$ at $40 \mathrm{~V}, 2.2 \mathrm{~nm} \mathrm{~V}^{-1}$ at $50 \mathrm{~V}$, and $1.9 \mathrm{~nm} \mathrm{~V}^{-1}$ at $60 \mathrm{~V}$. This interesting phenomenon fills a gap of our understanding of anodic porous alumina formation, especially when HHA can result in far better self-ordered patterns than MA (figure 4). The reason for this nonlinear relationship should be related to the differences between HHA and MA, namely, higher acid concentration and higher temperature for the former than latter. Thus, the two factors of acid concentration and temperature may potentially account for the nonlinear $D_{\text {int }}$ - voltage relation, and Figures 6(c) and (d) show their individual effects on the $D_{\text {int }}$. Figure 6(c) shows that $D_{\text {int }}$ decreases quickly with acid concentration increasing from 0.05 to $1 \mathrm{M} \mathrm{H}_{2} \mathrm{C}_{2} \mathrm{O}_{4}$ under $60 \mathrm{~V}$ at 20 ${ }^{\circ} \mathrm{C}$, by about $46.7 \mathrm{~nm}$ and $44.3 \mathrm{~nm}$ for patterns on (001) and (101) Al grains, respectively. In 
contrast, figure 6(d) shows that $D_{\text {int }}$ is almost independent of temperature for patterns formed on both (001) and (101) Al grains, with $D_{\text {int }}$ fluctuating around $101.5 \mathrm{~nm}$ with temperature increasing under $40 \mathrm{~V}$ and $0.4 \mathrm{M} \mathrm{H}_{2} \mathrm{C}_{2} \mathrm{O}_{4}$, or around $95.5 \mathrm{~nm}$ under $40 \mathrm{~V}$ and $0.8 \mathrm{M} \mathrm{H}_{2} \mathrm{C}_{2} \mathrm{O}_{4}$. Thus, the nonlinear relationship of $D_{\text {int }}$ against voltage is mainly due to the high acid concentration of HHA.

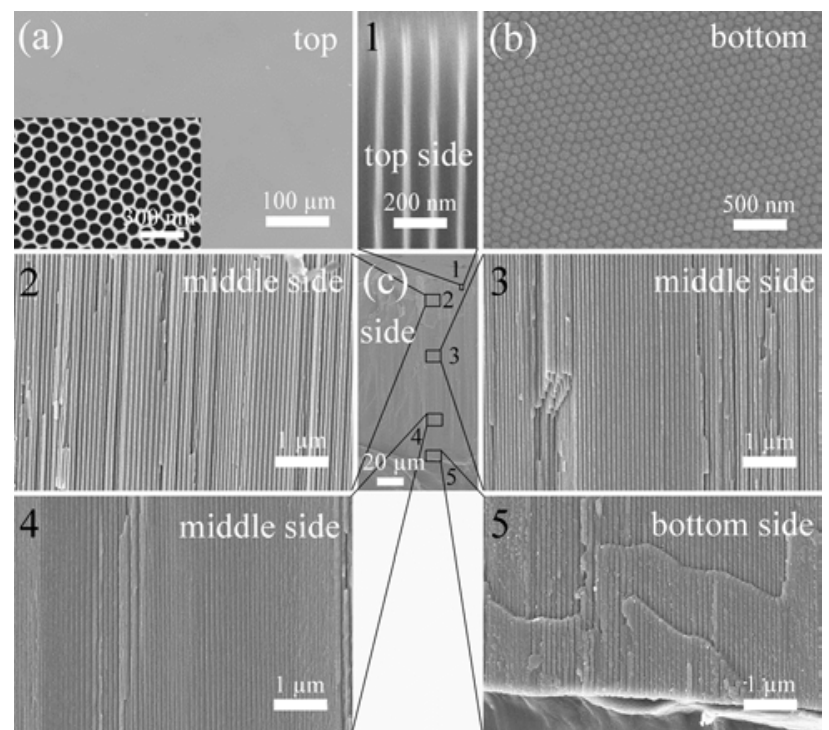

Figure 7. SEM of anodic porous alumina formed under $\mathrm{HHA}\left(0.9 \mathrm{M} \mathrm{H}_{2} \mathrm{C}_{2} \mathrm{O}_{4}, 20{ }^{\circ} \mathrm{C}\right)$ at $40 \mathrm{~V}$ after $7 \mathrm{~h}$ in the $2^{\text {nd }}$ step anodization (the previous $1^{\text {st }}$ step has $3 \mathrm{~h}$ ). (a) Top view, (b) bottom view (barrier layer) of anodic porous alumina after selectively dissolving the Al substrate. (c) Side view, with 1 to 5 high magnification sub-images from top to bottom of the porous alumina. Substrate grain orientation is not specified.

Recently, HA was regarded as a promising approach to replace the conventional MA for fast and self-ordered porous alumina fabrication [2, 20-24]. However, because of the high anodization voltages of HA, heat generation was very rapid during anodization [2], and as a result many macroscopic burns, cracks, or corrugations may form on the anodic porous alumina surface with sulfuric acid [20, 21] or oxalic acid as electrolyte (e.g. figures S1 (b) and (d) of Ref. 2). However, under our present optimum self-ordered condition (HHA $40 \mathrm{~V}$ ), even when the porous alumina has grown to $\sim 135 \mu \mathrm{m}$ thickness (figure $7(\mathrm{c})$ ), the surface of the porous alumina is still very smooth (low magnification image of figure 7(a)), without macroscopic burns, cracks, or corrugations appearing. As shown in the cross-sectional images of figures 7(c) 1 to 5 , most of the pore channels develop straightly from top to bottom with no splitting or termination observed. The porous pattern keeps the self-ordered arrangement from top (high magnification image of figure 7(a)) to the bottom of the porous structure (figure 7(c)). Taking an average value of $40 \mathrm{~nm}$ for the pore diameter $\left(D_{p}\right)$, the aspect ratio (= pore length/pore diameter) is about 3375, which is a very high value [2, 44]. Actually, due to the high concentrated $\mathrm{H}_{2} \mathrm{C}_{2} \mathrm{O}_{4}$ etching under high temperature of HHA, $D_{p}$ decreases from the pores' top to bottom, which are about 71, 55, 40, 30, and $25 \mathrm{~nm}$ in figures 7 (c) 1 to 5 , respectively. Thus, the planar porosity $=(\pi / 2 \sqrt{3}) /\left(D_{p} / D_{\text {int }}\right)^{2}$ of the anodic porous alumina decreases from $49.6 \%$ at the top to $6.2 \%$ at the bottom. Note that the porosity for self-ordered alumina was proposed to be 10\% under MA [45, 46], and 3\% under HA [2]; however, these rules are not suitable for self-ordered alumina formed under HHA. 

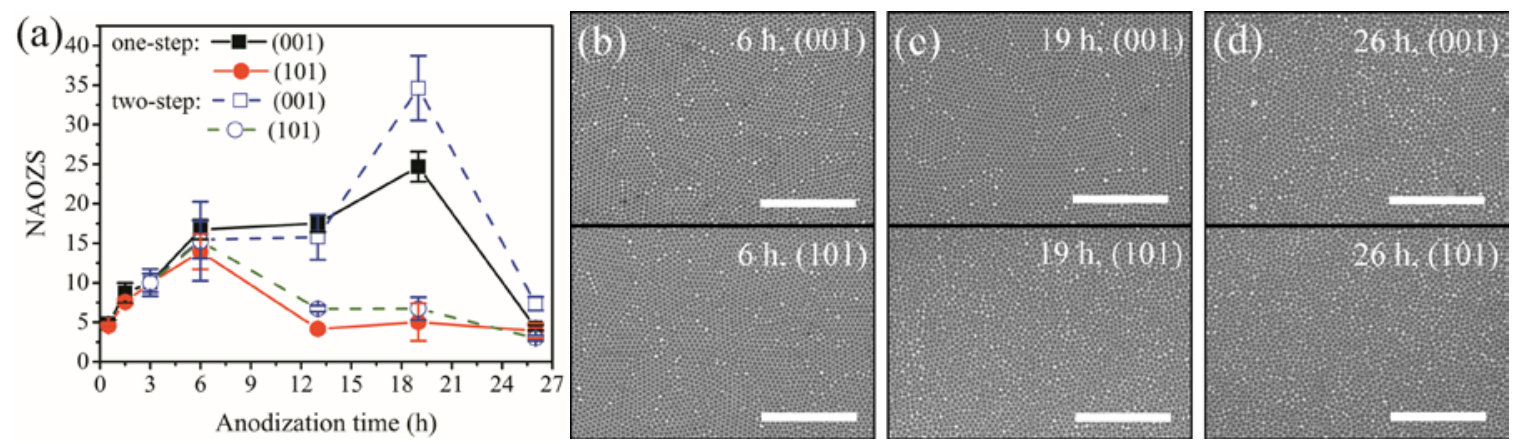

Figure 8. (a) Normalized average ordered zone size (NAOZS) of bottom porous patterns formed on (001) and (101) oriented $\mathrm{Al}$ grains against anodization time under $40 \mathrm{~V}, 0.5 \mathrm{M} \mathrm{H}_{2} \mathrm{C}_{2} \mathrm{O}_{4}$ and 5 ${ }^{\circ} \mathrm{C}$. For the two-step anodization (hollow symbols), the anodization time in the abscissa is the sum of $1^{\text {st }}$ step time ( $3 \mathrm{~h}$ ) and the $2^{\text {nd }}$ step time (variable). (b)-(d) Bottom porous patterns formed on (001) and (101) Al grains by one-step anodization for 6, 19 and $26 \mathrm{~h}$, respectively (scale bar = 2 $\mu \mathrm{m})$. Additional SEM images are shown in figure S8.

\subsection{Time dependent self-ordering of porous patterns}

Anodization time has been found to be an important factor for the self-ordering quality of anodic porous alumina [39, 45]; however, the effect of substrate grain orientation has not been considered together with the anodization time, which may lead to contradictory tendencies. Here, one-step and two-step anodization experiments were conducted with time increasing from 0.5 to $26 \mathrm{~h}$ (under $40 \mathrm{~V}, 0.5 \mathrm{M} \mathrm{H}_{2} \mathrm{C}_{2} \mathrm{O}_{4}, 5{ }^{\circ} \mathrm{C}$ ) to investigate pore ordering on (001) and (101) oriented $\mathrm{Al}$ grains. For the two-step anodization, the anodization time is the sum of the $1^{\text {st }}$ step time ( $\left.3 \mathrm{~h}\right)$ and $2^{\text {nd }}$ step time (variable). In figure 8(a), for one-step anodization, the NAOZS of patterns on (001) $\mathrm{Al}$ grains first increases to a maximum value of 24.7 after $19 \mathrm{~h}$, and then decreases to a minimum value of 4.3 after $26 \mathrm{~h}$, while on (101) Al grains, NAOZS only increases to a much smaller maximum value of 13.9 after $6 \mathrm{~h}$, and then decreases for the rest of time. During the beginning period ( $\mathrm{t} \leq 6 \mathrm{~h}$ ) and also the ending period ( $\mathrm{t} \sim 26 \mathrm{~h}$ ), the ordering difference between patterns on (001) and (101) grains is negligible (e.g. figures 8(b) and (d)), while only during an intermediate period (6 $\mathrm{h}<\mathrm{t}<26 \mathrm{~h}$ ) the difference is obvious (e.g. figures 8(c), S8). Thus, the advantage of (001) substrate orientation for better ordering pattern formation compared with (101) needs time to develop and actually vanishes when time is too long. The above situation also happens for the two-step anodization case, as the NAOZS values are quite close to those of the one-step case under the same anodization time (figure 8(a)). This also indicates that the advantage of the twostep anodization over the one-step for improving ordering is not obvious, except at $19 \mathrm{~h}$ on (001) oriented grains; instead, it is the total anodization time, rather than the number of anodization steps, which really affects the ordering of patterns. We can see that under a certain anodization condition, there is a limited ordering quality corresponding to a maximum NAOZS (e.g. 34.6 in figure 8(a)) that can be achieved with continuous increase of time. This limit is controlled by other factors combined together, including acid concentration, temperature, voltage, and substrate grain orientation. Recalling that under the condition of HHA $40 \mathrm{~V}$ on (001) oriented Al grains (figure $4(\mathrm{c})$ ), the NAOZS $=169.8$, which is about 5 times larger than the maximum NAOZS value in figure 8(a); while the $0.5 \mathrm{M}$ condition used in figure 8(a) can result in the best ordering pattern within the anodization group of $40 \mathrm{~V}, 5{ }^{\circ} \mathrm{C}$ (figure 2(a)). Thus the advantage of HHA for highly self-ordered pattern formation is significant.

\section{Conclusions}

In this work, key influencing factors for self-ordered anodic porous alumina formation including substrate $\mathrm{Al}$ grain orientation, electrolyte $\left(\mathrm{H}_{2} \mathrm{C}_{2} \mathrm{O}_{4}\right)$ concentration, temperature, voltage, and time are systemically investigated by a series of anodization experiments. The ordering qualities of 
porous patterns are quantitatively evaluated by a coloring scheme based on the orientations of triangles formed by joining three nearest neighboring pore centers. For patterns formed on both (001) and (101) oriented Al grains, the NAOZS monotonously increases with acid concentration and temperature, while this increases first and then decreases with anodization voltage and time. (001) substrate orientation can result in better self-ordering patterns than (101) if other processing factors are within the self-ordering window; otherwise patterns formed on both grain orientations will be similarly disordered.

Besides the conventional MA and HA conditions, an alternative anodization condition HHA is found. Compared with MA condition, HHA can result in far better self-ordered porous patterns under a continuous anodization voltage range of 30-60 V on (001) oriented $\mathrm{Al}$ grains, and this represents a significant extension of the previously found processing windows for self-ordering with $\mathrm{H}_{2} \mathrm{C}_{2} \mathrm{O}_{4}$ as the electrolyte. The HHA condition provides much wider choices of self-ordered porous structures, with interpore distances ranging from 74.5 to $112.0 \mathrm{~nm}$, for potential nanotechnology applications. The oxide growth rate of HHA is found to be $3.18 \mathrm{e}^{\mathrm{voltage} / 30}$ times faster than MA, i.e. 7 to 26 times faster under 30 to $60 \mathrm{~V}$. Moreover, compared with HA, macroscopic burns, cracks, or corrugations are not observed on alumina surface under the optimum self-ordered condition HHA $40 \mathrm{~V}$, even for oxide grown up to $135 \mu \mathrm{m}$ thickness with high aspect ratios $>3000$. Furthermore, different from the well-known linear relationship under MA or HA, the $D_{\text {int }}$ to anodization voltage ratio is nonlinear under HHA, and this is mainly due to the high acid concentration of HHA condition.

\section{Supporting information}

Additional figures including low magnification SEM images of Al substrate and RDF curves for porous patterns in figure 1; SEM images of porous patterns corresponding to figures 2, 3, 4, and 8; colored anodic porous alumina patterns formed under HHA 30-60 V for figure 5.

\section{Acknowledgments}

This work was supported by grants from the Research Grants Council (Project No. HKU7159/10E), as well as from the University Grants Committee (Project No. SEG-HKU06) of the Hong Kong Special Administration Region, P.R. China. This work was inspired by earlier experiments carried out by Dr. K.Y. Ng, who also designed the anodization cell used in the present experiments.

\section{References}

[1] Masuda H and Fukuda K 1995 Science 2681466

[2] Lee W, Ji R, Gösele U and Nielsch K 2006 Nat. Mater. 5741

[3] Lee W, Schwirn K, Steinhart M, Pippel E, Scholz R and Gösele U 2008 Nat. Nanotechnol. 3 234

[4] Houser J E and Hebert K R 2009 Nat. Mater. 8414

[5] Ng C K Y and Ngan A H W 2011 Chem. Mater. 235264

[6] Masuda H and Satoh M 1996 Jpn. J. Appl. Phys. 35 L126

[7] Liu L, Pipel E and Scholz R and Gösele U 2009 Nano Lett. 94352

[8] Huang Z, Zhang X, Reiche M, Liu L, Lee W, Shimizu T, Senz S and Gösele U 2008 Nano Lett. 83046

[9] Chun H, Hahm M G, Homma Y, Meritz R, Kuramochi K, Menon L, Ci L, Ajayan P M and Jung Y J 2009 ACS Nano 31274

[10] Lee W, Scholz R and Gösele U 2008 Nano Lett. 82155

[11] Chik H and Xu J M 2004 Mater. Sci. Eng. R 43103

[12] Masuda H, Abe A, Nakao M, Yokoo A, Tamamura T and Nishio K 2005 Adv. Mater. 15161

[13] Masuda H, Yamada M, Matsumoto F, Yokoyama S, Mashiko S, Nakao M and Nishio K 2006 Adv. Mater. 18213 
[14] Lee W, Han H, Lotnyk A, Schubert M A, Senz S, Alexe M, Hesse D, Baik S and Gösele U 2008 Nat. Nanotechnol. 3402

[15] Bennett S P, Menon L and Heiman D 2008 J. Appl. Phys. 104024309

[16] Choi W B, Chu J U, Jeong K S, Bae E J, Lee J W, Kim J J and Lee J O 2001 Appl. Phys. Lett. 793696

[17] Masuda H, Hasegwa F and Ono S 1997 J. Electrochem. Soc. 144 L127

[18] Masuda H, Yada K and Osada A 1998 Jpn. J. Appl. Phys. 37 L1340

[19] Martín J, Manzano C V, Caballero-Calero O, Martín-González M 2013 ACS Appl. Mater. Interfaces 572

[20] Shwirn K, Lee W, Hillebrand R, Steinhart M, Nielsch K and Gösele U 2008 ACS Nano 2

302

[21] Chu S Z, Wada K, Inoue S, Isogai M and Yasumori A 2005 Adv. Mater. 172115

[22] Lee W, Kim J C and Gösele U 2010 Adv. Funct. Mater. 2021

[23] Losic D, Lillo M and Losic D 2009 Small 51392

[24] Losic D and Losic D 2009 Langmuir 255426

[25] Houser J E and Hebert K R 2006 J. Electrochem. Soc. 153 B566

[26] Cheng C and Ngan A H W 2011 Electrochim. Acta 569998

[27] Ng K Y and Ngan A H W 2012 Scripta Mater. 66439

[28] Ng K Y, Lin Y and Ngan A H W 2009 Acta Mater. 572710

[29] Beck G and Bretzler R 2011 Mater. Chem. Phys. 128383

[30] Beck G and Retrikowski K 2008 Surf. Coat. Tech. 2025084

[31] Napolskii K S, Roslyakov I V, Romanchuk A Y, Kapitanova O O, Mankevich A S, Lebedev V A and Eliseev A A 2012 J. Mater. Chem. 221192

[32] O'Sullivan J P and Wood G C 1970 Proc. R. Soc. London A 317511

[33] Lei Y, Cai, W and Wilde G 2007 Prog. Mater. Sci. 52465

[34] Losic D, Shapter J G, Mitchell J G and Voelcker N H 2005 Nanotechnology 162275

[35] Yanagishita T, Nishio K and Masuda H 2005 Adv. Mater. 172241

[36] Lee W, Scholz R, Nielsch K and Gösele U 2005 Angew. Chem. 1176204

[37] Leonardi S, Bassi A L, Russo V, Fonzo F D, Paschos O, Murray T M, Efstathiadis H and Kunze J 2012 J. Phys. Chem. C 116384

[38] Cheng C, Ng K Y and Ngan A H W 2011 AIP Adv. 1042113

[39] Hillebrand R, Müller F, Schwirn K, Lee W and Steinhart M 2008 ACS Nano 2913

[40] Mátéfi-Tempfli S, Mátéfi-Tempfli M and Piraux L 2008 Thin Solid Films 5163735

[41] Rasband W 2011 ImageJ, release 1.44, NIH: USA (public domain, http://rsb.info.nih.gov/ij/).

[42] Lu B, Bharathulwar S, Laughlin D E and Lambeth D N 2000 J. Appl. Phys. 874721

[43] Friedman A L and Menon L 2007 J. Appl. Phys. 101084310

[44] Lee W, Ji R, Ross C A, Gösele U and Nielsch K 2006 Small 2978

[45] Nielsch K, Choi J, Schwim K, Wehrspohn R B and Gösele U 2002 Nano Lett.2 677

[46] Ono S, Saito M, Ishiguro M and Asoh H 2004 J. Electrochem. Soc. 151 B473 